\title{
Covalently Adaptable Hydrogel Based on Hyaluronic Acid and Poly( $\gamma$-Glutamic Acid) for Potential Load-Bearing Tissue Engineering
}

Xuebin Ma, $\uparrow, \ddagger, \S$ Xin Liu,,$\uparrow$ Penghui Wang,, Xiaoxue Wang, $\uparrow$ Rong Yang, $\uparrow$ Shuai Liu,, Zhiwen Ye, $\ddagger$ Bo Chi, ${ }^{*} \dagger$

$\uparrow$ State Key Laboratory of Materials-Oriented Chemical Engineering, College of Food Science and Light Industry, Nanjing Tech University, Nanjing, China

$\ddagger$ School of Chemical Engineering, Nanjing University of Science and Technology, Nanjing,

China

$\S$ Key Laboratory of Colloid and Interface Chemistry of the Ministry of Education, School of Chemistry and Chemical Engineering, Shandong University, Jinan, China

Corresponding Author*: chibo@njtech.edu.cn 


\section{Experimental Section}

\section{Materials}

Sodium periodate $\left(\mathrm{NaIO}_{4}\right)$, glycidyl methacrylate (GMA), adipic acid dihydrazide (ADH), 1ethyl-3-(3-dimethylaminopropyl)-carbodiimide $(\mathrm{EDC} \cdot \mathrm{HCl}), \mathrm{N}$-hydroxy-succinimide (NHS) were bought from Aladdin Industrial Corporation (Shanghai, China).

\section{Modification and Characterization of Biopolymers}

\section{Synthesis of HA-CHO ${ }^{1}$}

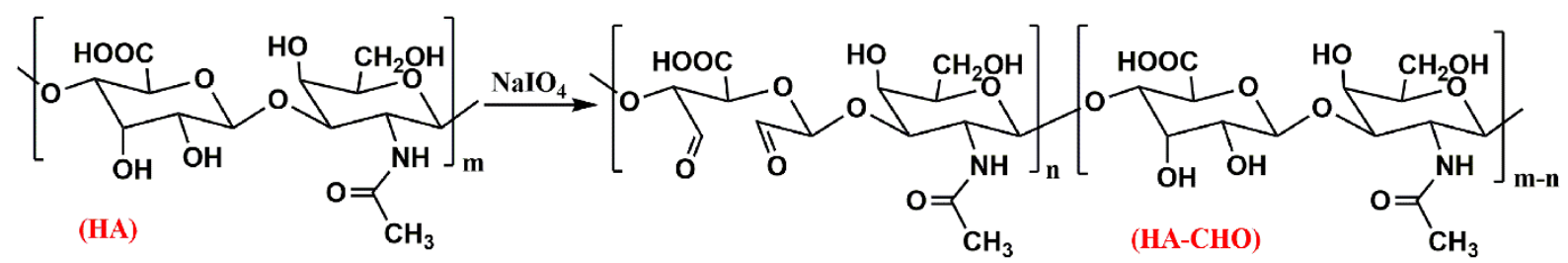

HA was dissolved in deionized water to obtain a $1 \mathrm{wt} \%$ solution, then $\mathrm{NaIO}_{4}$ solution $(0.5$ $\mathrm{mol} / \mathrm{L}$ ) was added dropwise. The molar ratio of $\mathrm{NaIO}_{4}$ to $\mathrm{HA}$ was set at 2:1. Oxidation reaction proceeded at $30^{\circ} \mathrm{C}$ in the dark for $2.5 \mathrm{~h}$. Then excess amount of ethylene glycol was added to inactivate any unreacted periodate for $1 \mathrm{~h}$. The solution was purified by dialysis against deionized water for 3 days, and dry product was obtained by lyophilization. The synthesized HA-CHO was confirmed by ${ }^{1} \mathrm{H}$ NMR spectra. As shown in Figure S1, the peaks at 4.95 5.25 ppm belong to the hemiacetalic proton formed from aldehyde and adjacent hydroxyl groups. ${ }^{2,3}$ The oxidation degree determined by the hydroxylamine hydrochloride titration method ${ }^{4}$ was $22.1 \%$

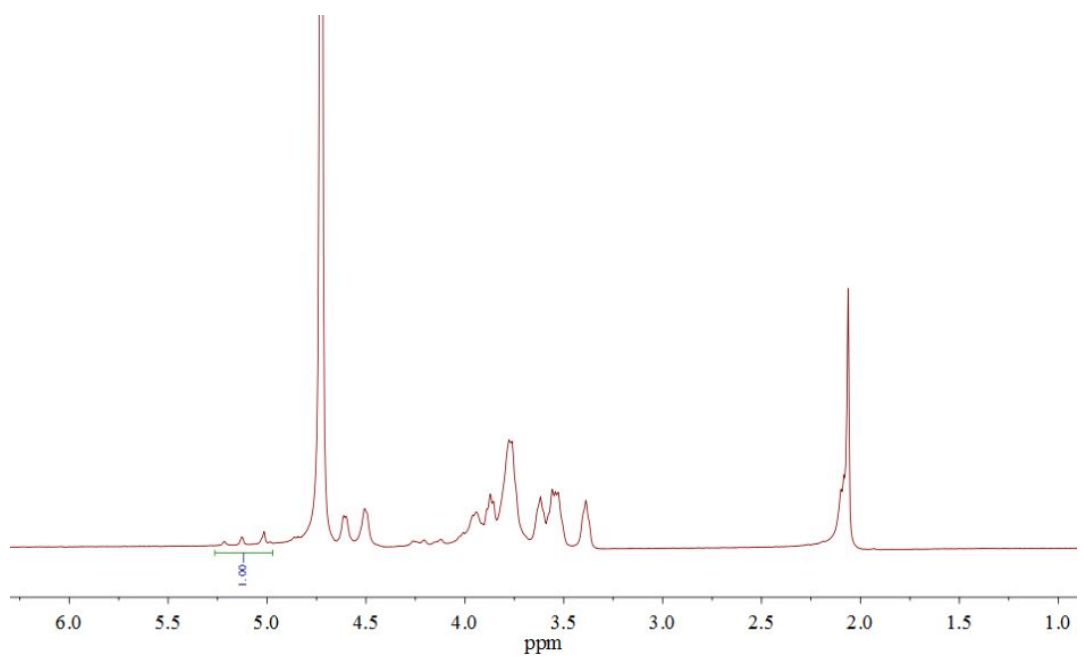

Figure S1 ${ }^{1} \mathrm{H}-\mathrm{NMR}$ spectrum of $\mathrm{HA}-\mathrm{CHO}$ 


\section{Synthesis of $\gamma$-PGA-ADH ${ }^{4}$}<smiles>CCC(=O)CCC(NC(C)C)C(=O)O</smiles>

$(\gamma$-PGA)<smiles>NNC(=O)CCCCC(N)=O</smiles>

(ADH)

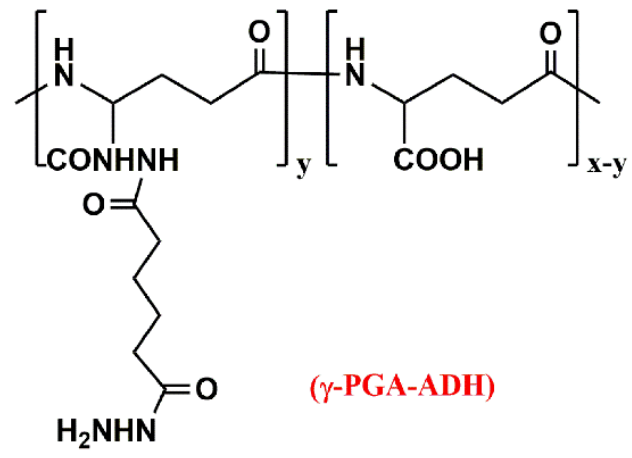

$\gamma$-PGA was dissolved in deionized water to obtain a $1 \mathrm{wt} \%$ solution, and then reacted with ADH in the presence of EDC and NHS. The molar ratio of $-\mathrm{COOH}$ (of $\gamma$-PGA) to ADH was 1:1.5, whereas $-\mathrm{COOH}$ ( of $\gamma$-PGA):EDC:NHS was $1: 1.2: 1.2$. The $\mathrm{pH}$ of reaction mixture was adjusted to 5.5 by adding a $0.1 \mathrm{~mol} / \mathrm{L} \mathrm{HCl}$ solution. Reaction was allowed to proceed at $30^{\circ} \mathrm{C}$ for $24 \mathrm{~h}$. Then, the reaction solution was dialyzed against deionized water for 3 days followed by lyophilization. As shown in Figure S2, a new peak at $1.46 \mathrm{ppm}$ corresponding to the methylene protons of $\mathrm{ADH}$ was observed, indicating the successful conjugation of ADH to $\gamma$-PGA. ${ }^{4}$ Hydrazide functionalization determined by comparing the integrals areas of signals at $1.45 \sim 1.75$ ppm (ADH, methylene protons, $4 \mathrm{H}$ ) and 4 4.5 ppm ( $\gamma$-PGA, $\alpha$-protons, $1 \mathrm{H}$ ) was $36.2 \%$.

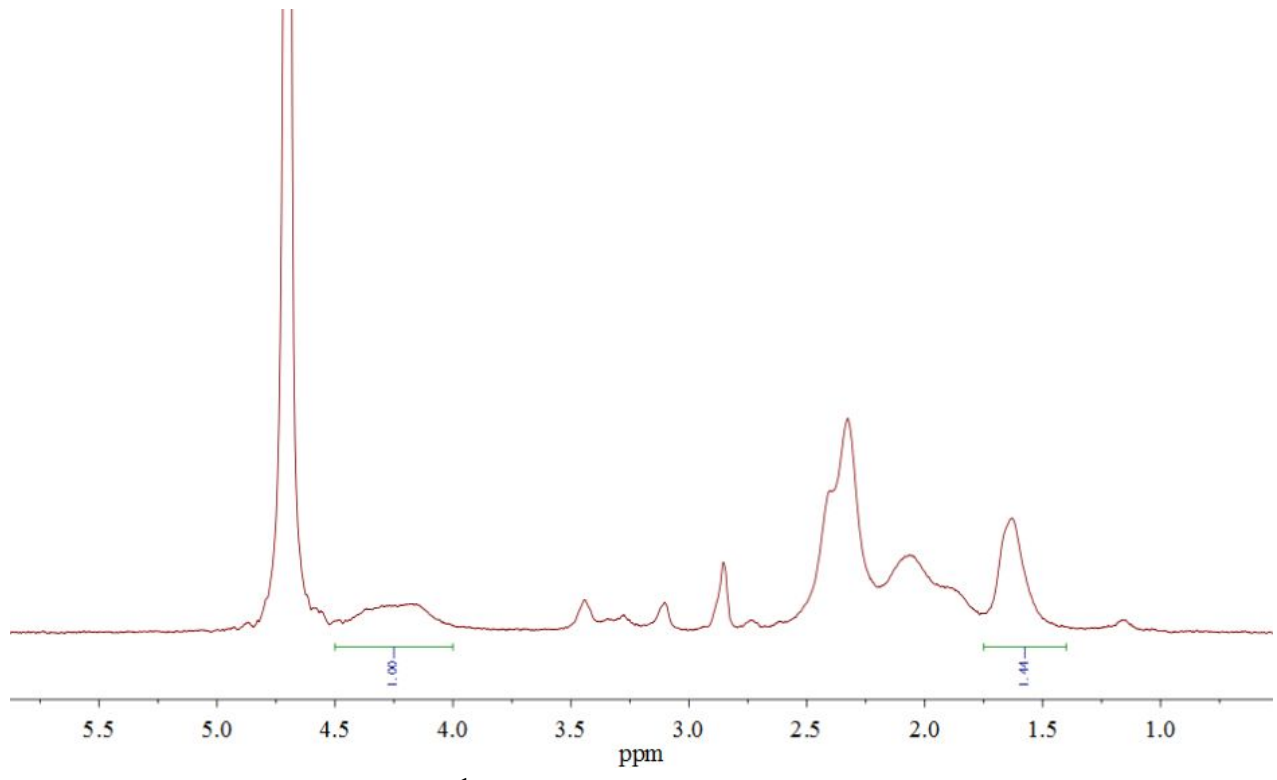

Figure S2 ${ }^{1} \mathrm{H}-\mathrm{NMR}$ spectrum of $\gamma$-PGA-ADH 


\section{Synthesis of $\gamma$-PGA-GMA ${ }^{5}$}<smiles>CC(C)NC(CCC(=O)CI)C(=O)O</smiles><smiles>C=C(C#N)C(=O)OCC1CO1</smiles>

(GMA)
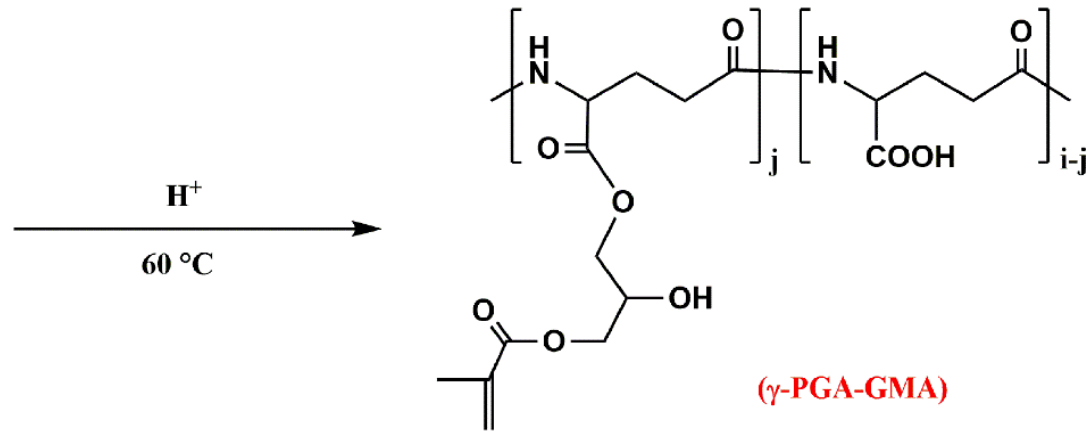

$\gamma$-PGA was dissolved in deionized water to obtain a $1 \mathrm{wt} \%$ solution, then GMA was added under stirring, and the molar ratio of GMA: $-\mathrm{COOH}$ ( of $\gamma$-PGA) was set at $0.5: 1$. The $\mathrm{pH}$ of the reaction mixture was adjusted to $4.5 \sim 5.0$ and the reaction proceeded at $60^{\circ} \mathrm{C}$ for $6 \mathrm{~h}$. After that, the reaction solution was purified by exhaustive dialysis against deionized water for $72 \mathrm{~h}$ and the dry product was obtained by freeze-drying. The synthesized $\gamma$-PGA-GMA was confirmed by ${ }^{1} \mathrm{H}$ NMR spectra. As shown in Figure S3, the peaks at $\delta 5.64 \sim 6.27$ ppm observed in $\gamma$-PGA-GMA spectrum indicated the successful conjugation of GMA to $\gamma$-PGA. ${ }^{6}$ The degrees of methacrylation calculated by comparing the integrals areas of signals at $\delta 5.64 \sim 6.27 \mathrm{ppm}$ (GMA, vinyl protons) to 4.0 4.4 ppm $(\gamma$-PGA, $\alpha$-protons) was $13.5 \%$.

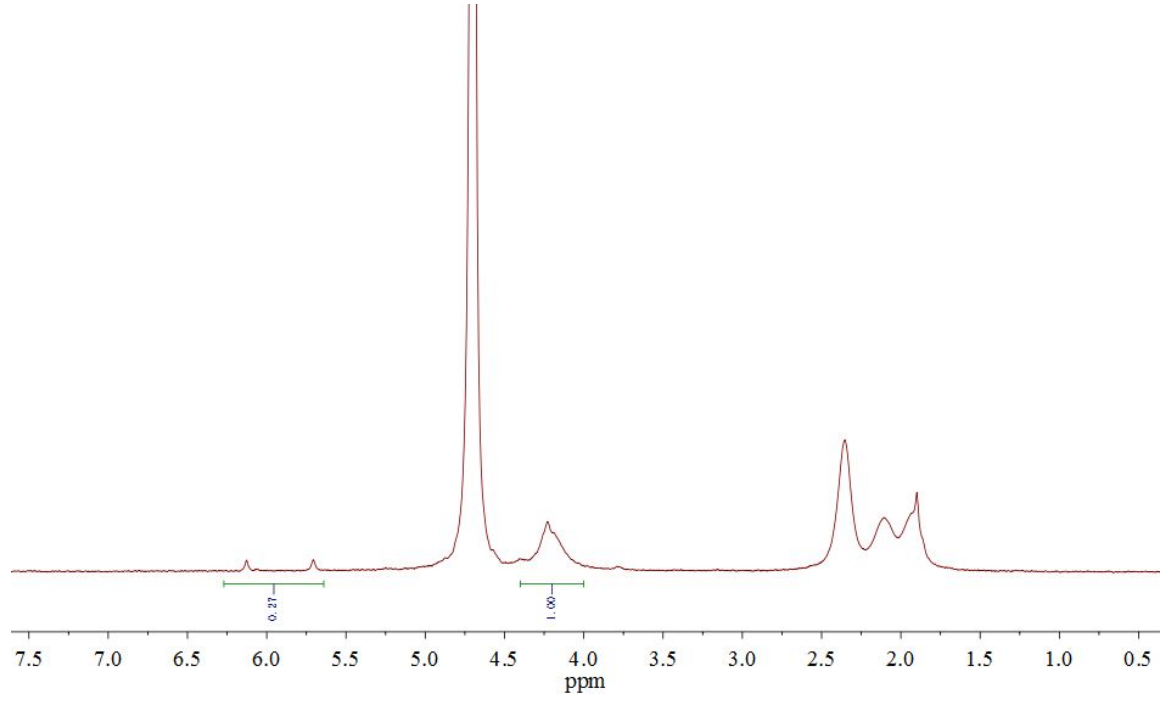

Figure $\mathbf{S 3}{ }^{1} \mathrm{H}-\mathrm{NMR}$ spectrum of $\gamma$-PGA-GMA 


\section{Characterization of hydrogels}

Gelation time of SIPN hydrogels was measured by the vial tilting method. The mixture of $\gamma$ PGA-ADH and $\gamma$-PGA-GMA was rapidly mixed with the HA-CHO solution in a vial. The time until the mixtures don't flow was considered as the gelation time. This test was carried out in triplicate.

The swelling behaviors of IPN hydrogels were studied by the following steps: (1) the IPN hydrogels $(300 \mu \mathrm{L})$ were prepared in a cylinder mold and then immersed in PBS solution at $37^{\circ} \mathrm{C}$. At different intervals, the swollen IPN hydrogels were taken out and removed the surface water, then weighed $\left(W_{s}\right)$ immediately; (2) the prepared IPN hydrogels $(300 \mu \mathrm{L})$ were lyophilized and weighed $\left(W_{d}\right)$. The swelling ratio was expressed as $\left(W_{s}-W_{d}\right) / W_{d}$ and this test was carried out three times.

Microporous morphologies of the lyophilized hydrogels were examined by scanning electron microscopy (SEM, Hitachi, SU1510, Japan). Firstly, the hydrogels prepared in a cylinder mold were frozen at $-80^{\circ} \mathrm{C}$ and vacuum lyophilized at $-50^{\circ} \mathrm{C}$ for $48 \mathrm{~h}$, then the lyophilized hydrogels were broken off and the cross-sectionals were gold coated and observed by SEM.

To test the enzymatic degradation of hydrogels, the hydrogel samples were prepared in a cylinder mold then lyophilized and weighed $\left(W_{0}\right)$. The dried hydrogels were incubated in PBS solution with $0.1 \mathrm{mg} / \mathrm{mL}$ of hyaluronidase and $0.25 \mathrm{mg} / \mathrm{mL}$ of papain at $37{ }^{\circ} \mathrm{C}$. Sample in PBS without enzyme was used as blank. At predetermined intervals, the hydrogels were taken out and lyophilized to obtain the dried mass $\left(W_{t}\right)$. The solution was replaced every time with a fresh solution. This experiment was performed in triplicate and the degree of degradation was defined as: Weight remaining $(\%)=\left(W_{t} / W_{0}\right) \times 100 \%$

Thermo gravimetry analysis (TGA) measurements of HA-GMA, $\gamma$-PGA-GMA and HA/ $\gamma-\mathrm{PGA}$ hydrogel were performed using a thermogravimetry instrument (HENGJIU, HCT-2, China) under nitrogen atmosphere. The temperature range was set as $35 \sim 700^{\circ} \mathrm{C}$, and the heat rate was $10^{\circ} \mathrm{C} / \mathrm{min}$.

Rheological measurements were carried out with an Anton Paar rheometer (MCR302) using a $25 \mathrm{~mm}$ plate-plate sensor. The linear viscoelastic regions of hydrogel samples were determined by Strain sweep at $1 \mathrm{~Hz}$. The viscoelastic behaviors of hydrogels were evaluated via oscillatory frequency sweeps which were performed at a fixed strain of $1 \%$ at $25^{\circ} \mathrm{C}$.

The compressive properties of hydrogels were studied by unconfined compression tests using a universal material testing instrument (MTS, CMT2103, USA). Firstly, hydrogels (500 $\mu$ L) were prepared in a $1 \mathrm{~cm}$ diameter cylindrical mold. Then the compression test was carried out at a controlled rate $10 \mathrm{~mm} / \mathrm{min}$. The cyclic compression test was performed by undergoing 5 cycles of compression. The compressive modulus was determined using the slope of the initial linear region of stress-strain curves. 


\section{In vitro $\mathrm{BSA}$ release}
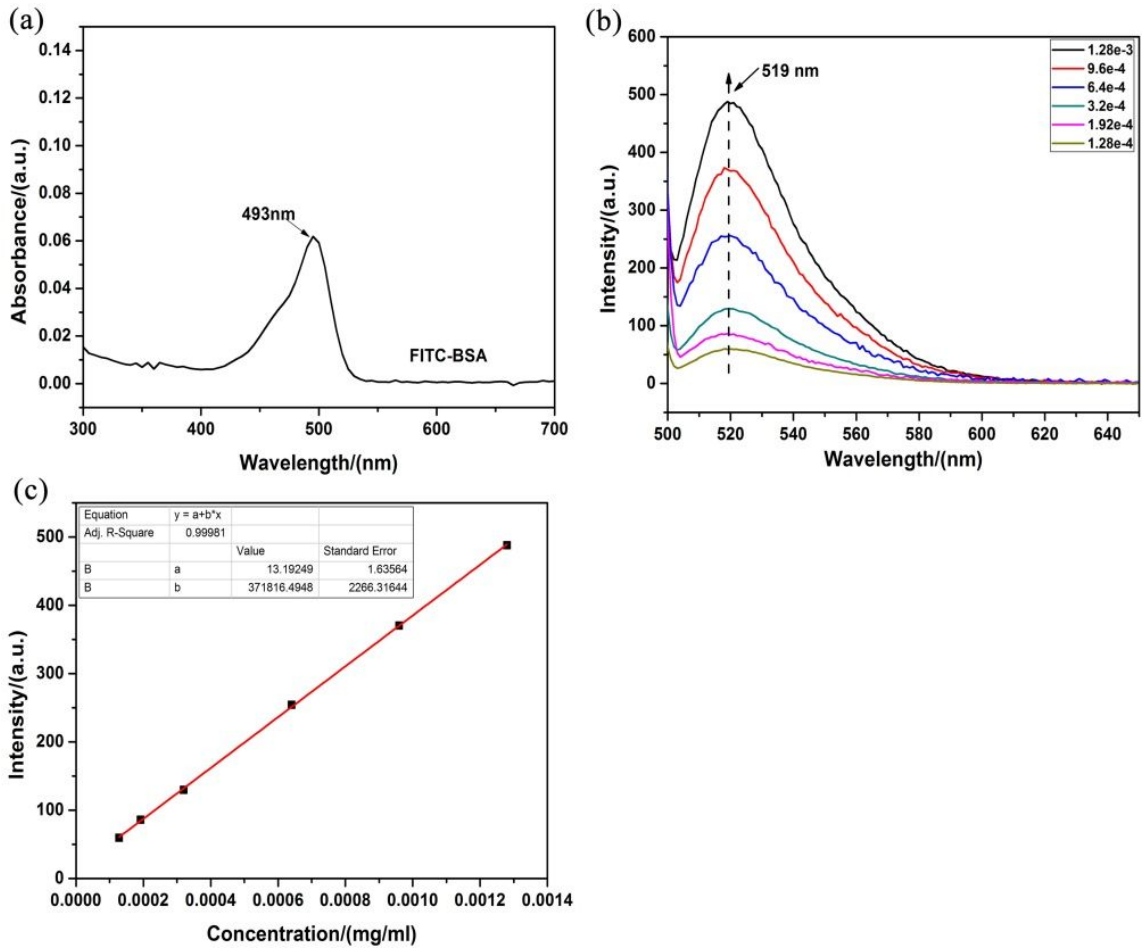

Figure S4 (a) Ultraviolet absorption curve of FITC-BSA. (b) Fluorescence spectrums of FITCBSA with different concentration excited by $493 \mathrm{~nm}$ UV light. (c) Standard curve of FITC-BSA in PBS vs fluorescence intensity.

The drug release tests were performed by immersing BSA-loaded HA/ $\gamma$-PGA hydrogels in 10 $\mathrm{mL}$ PBS with occasionally shaking at $37^{\circ} \mathrm{C}$. At different times, the release medium $(4 \mathrm{~mL})$ was taken out and replaced with an equal volume of PBS. BSA concentration was quantified using spectrofluorometer (RF-5301/PC, SHIMADZU, Japan) at $519 \mathrm{~nm}$. The total amount of BSA was calculated using a standard curve of FITC-BSA in PBS versus fluorescence intensity (Figure S4).

The kinetics of drug release from $\mathrm{HA} / \gamma$-PGA hydrogels was studied by several mathematical models. The mechanistic models are described below:

Zero-order: $\frac{M_{t}}{M_{\infty}}=k_{0} t$

First-order: $\frac{M_{t}}{M_{\infty}}=1-e^{-K_{1} t}$

Where $M_{t} / M_{\infty}$ is the fraction of drug released at time t. $K_{0}$ and $K_{l}$ represent the zero-order and first-order release kinetic constant, respectively.

Korsmeyer-Peppas model: ${ }^{7} \frac{M_{t}}{M_{\infty}}=K t^{n}$ 
Where $K$ is a constant incorporating structural and geometric characteristic of the drug dosage form, and $n$ is the release exponent. The initial portion of the release curve $\left(M_{t} / M_{\infty}<0.6\right)$ was used to determine $n{ }^{7,8}$ For the drug release mechanism of cylindrical samples: $n=0.45$ suggests Fickian diffusion with a negligible relaxation coefficient; $n=0.89$ refers to a non-Fickian with the characteristic of zero order release; if $0.45<n<0.89$, the transport process is anomalous with a comparable structural relaxation to diffusion; ${ }^{8} n<0.45$ indicates a pseudo-Fickian diffusion with a relative slow release that positively relied on the $n$ value. $^{2}$

\section{Cytotoxicity assay}

Biocompatibility evaluation of polymers HA-CHO, $\gamma$-PGA-ADH and $\gamma$-PGA-GMA were carried out using NIH 3T3 mouse fibroblast (National platform of experimental cell resources for science-technology, Shanghai, China). These polymers were dissolved in DMEM containing FBS $(10 \%)$ and penicillin-streptomycin $(1 \%)$ to obtain different concentrations $(0.1,0.2,0.5,1$ and 2 $\mathrm{mg} / \mathrm{mL}$ ) polymer solutions, respectively. Then the polymer solutions were sterilized by filtrating via $0.22 \mu \mathrm{m}$ syringe filter. NIH $3 \mathrm{~T} 3$ cells were seeded in 96 -well culture plate $\left(5 \times 10^{4}\right.$ cells $/ \mathrm{mL}$, $100 \mu \mathrm{L} /$ well) and cultured in an incubator (HERA cell $150 \mathrm{i}$, Thermo, USA) at $37^{\circ} \mathrm{C}$ and $5 \% \mathrm{CO}_{2}$. $12 \mathrm{~h}$ later, the culture medium was replaced with $100 \mu \mathrm{L}$ polymer solutions respectively. After culturing $24 \mathrm{~h}$, the cell viabilities were evaluated by MTT assay. The morphology and live/dead behavior of cells cultured in $2 \mathrm{mg} / \mathrm{mL}$ polymer solutions were tested. After 1-, 2- and 3-days cultivation, NIH $3 \mathrm{~T} 3$ cells were stained with $\mathrm{AO} / \mathrm{EB}$, and then visualized by an inversed fluorescent microscope (Olympus, TH4-200, Japan). Cultures in medium without polymer solutions were used as control.

\section{Statistical Analysis}

Data were expressed as mean \pm standard deviation. Statistical differences were performed using one-way ANOVA followed by post hoc Tukey honestly significant difference (HSD) test, and statistical significance was accepted at $\mathrm{P}<0.05$. 


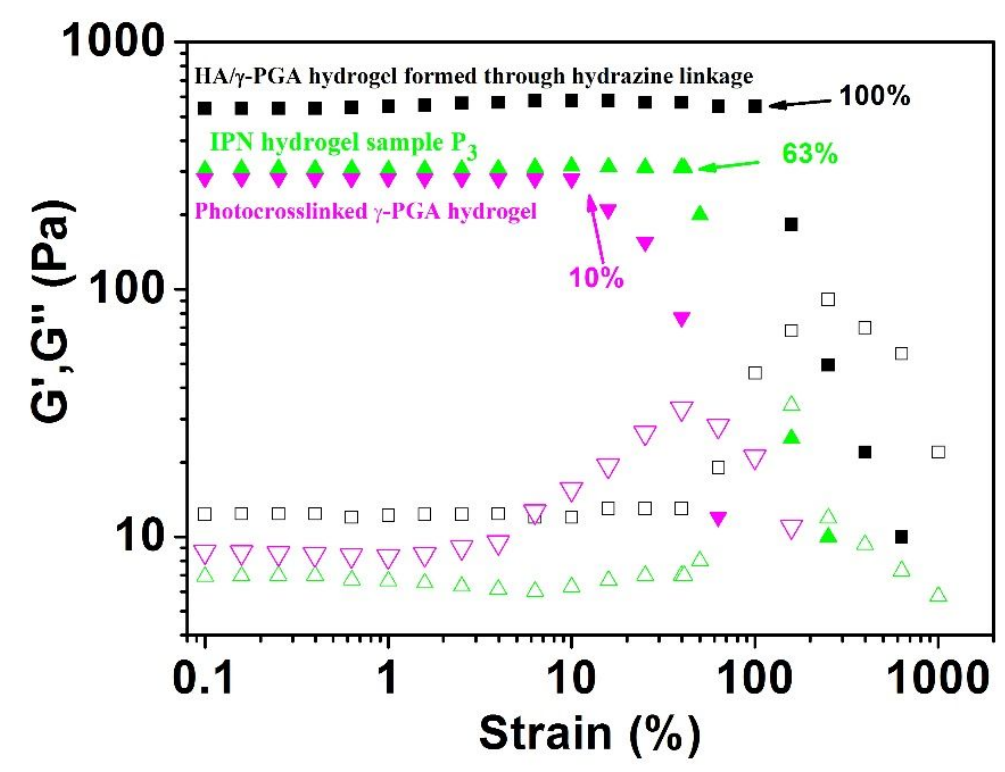

Figure S5 Strain sweep curves of HA $/ \gamma$-PGA hydrogel formed through hydrazine linkage at $5 \mathrm{wt} \%$, photocrosslinked $\gamma$-PGA hydrogel at $5 \mathrm{wt} \%$, and IPN hydrogel sample $\mathrm{P}_{4}$.

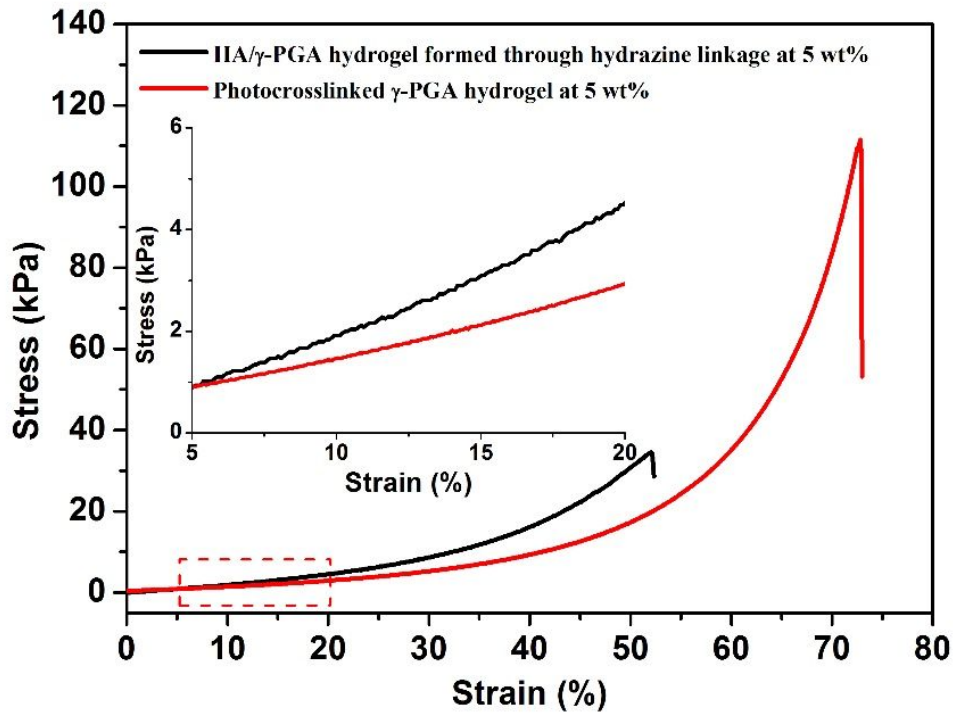

Figure S6 Stress-strain curves of HA/ $\gamma$-PGA hydrogel formed through hydrazine linkage at $5 \mathrm{wt} \%$ and photocrosslinked $\gamma$-PGA hydrogel at $5 \mathrm{wt} \%$. The inset is the enlarged image of stress-strain curve for strain ranging from 5 to $20 \%$. 

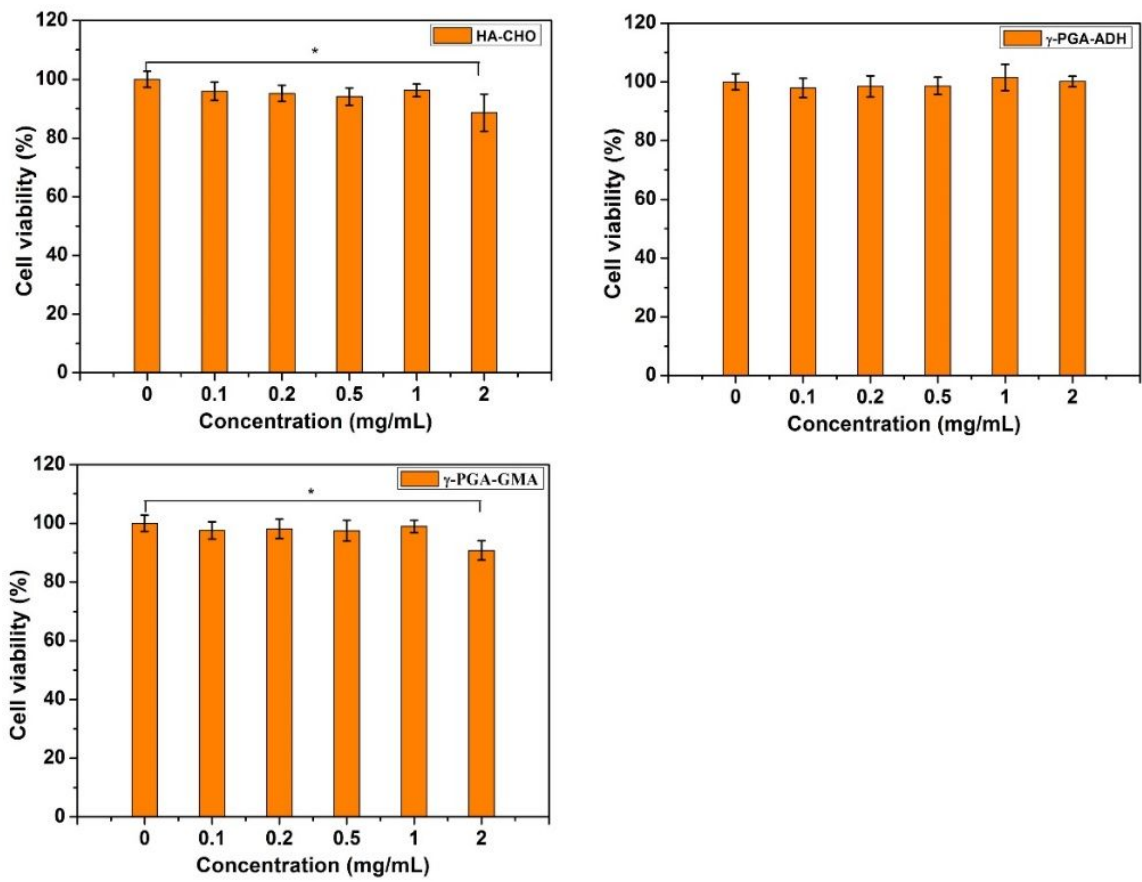

Figure S7 Viability of NIH 3T3 cells cultured with different concentrations of functionalized polymer solutions for $24 \mathrm{~h} .\left(\mathrm{n}=3,{ }^{*} \mathrm{p}<0.05\right)$.
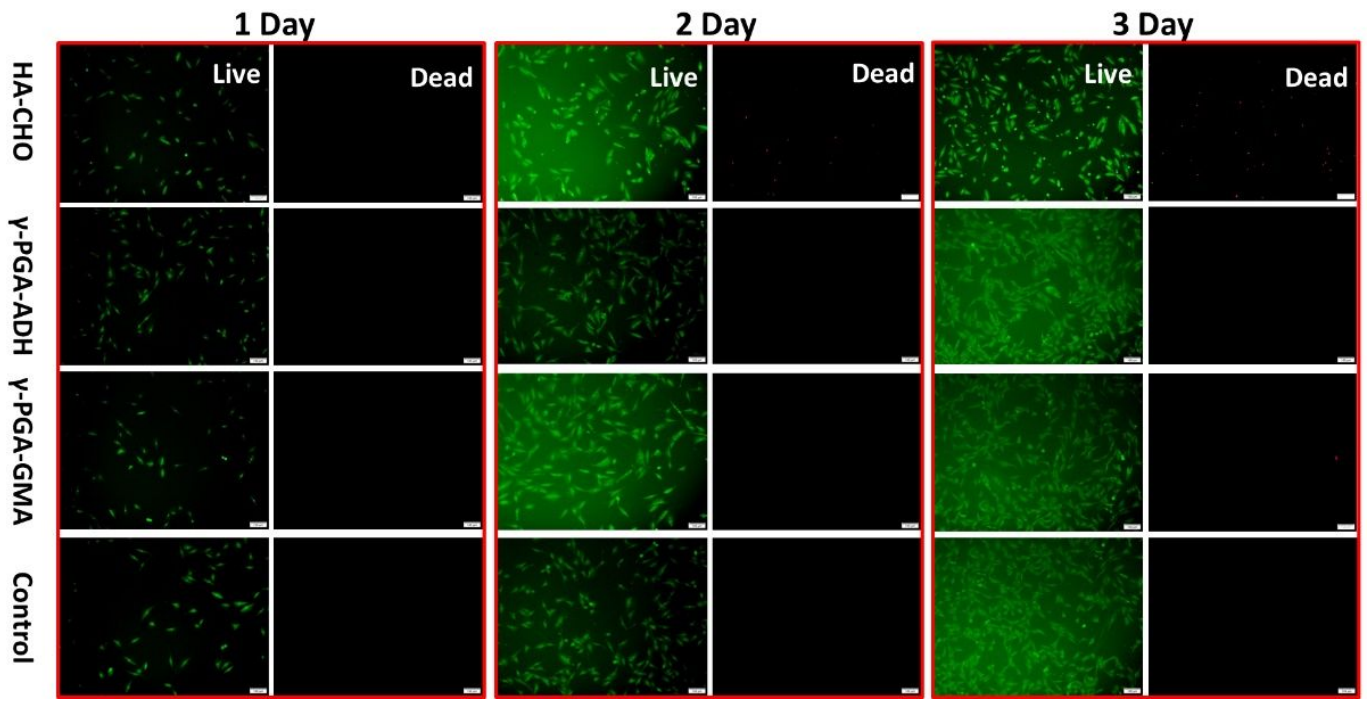

Figure S8 Fluorescence images of live (green)/dead (red) NIH 3T3 cells cultured with $2 \mathrm{mg} / \mathrm{mL}$ HA-CHO, $\gamma$-PGA-ADH and $\gamma$-PGA-GMA solutions for 1-, 2- and 3-days, respectively. Cultures in medium without functionalized polymer were used as control.

\section{Supplementary References}

(1) Ito, T.; Yeo, Y.; Highley, C. B.; Bellas, E.; Benitez C. A.; Kohane, D. S. The Prevention of Peritoneal Adhesions by in situ Cross-Linking Hydrogels of Hyaluronic Acid and Cellulose 
Derivatives. Biomaterials 2007, 28, 975-983.

(2) Li, N. N.; Fu, C. P.; Zhang, L. M. Using Casein and Oxidized Hyaluronic Acid to Form Biocompatible Composite Hydrogels for Controlled Drug Release. Mat. Sc. Eng. C 2014, 36, $287-$ 293.

(3) Li, L.; Wang, N.; Jin, X.; et al. Biodegradable and Injectable in situ Cross-Linking ChitosanHyaluronic Acid Based Hydrogels for Postoperative Adhesion Prevention. Biomaterials, 2014, 35 , 3903-3917.

(4) Yan, S.; Wang, T.; Feng, L.; Zhu, J.; Zhang, K.; Chen, X.; Cui, L.; Yin, J. Injectable In Situ Self-Cross-Linking Hydrogels Based on Poly( ${ }_{\mathrm{L}}-$ Glutamic Acid) and Alginate for Cartilage Tissue Engineering. Biomacromolecules 2014, 15, 4495-4508.

(5) Zhuang, H.; Hong, Y.; Gao, J.; Chen, S.; Ma, Y.; Wang, S. A Poly $(\gamma-$ Glutamic Acid)-Based Hydrogel Loaded with Superoxide Dismutase for Wound Healing. J. Appl. Polym. Sci. 2015, 132, 42033.

(6) Huh, H.W.; Zhao, L.; Kim, S.Y. Biomineralized Biomimetic Organic/Inorganic Hybrid Hydrogels Based on Hyaluronic Acid and Poloxamer. Carbohyd. Polym. 2015, 126, 130-140.

(7) Korsmeyer, R.W.; Gurny, R.; Doelker, E.; Buri, P.; Peppas, N.A. Mechanisms of Solute Release from Porous Hydrophilic Polymers. Int. J. Pharmaceut. 1983, 15, 25-35.

(8) Costa, P.; Lobo, J. M. S. Modeling and Comparison of Dissolution Profiles. Eur. J. Pharm. Sci. 2001, 13, 123-133. 